\title{
Erratum
}

Ophthalmologe 2021 118 (Suppl 2):S177-S178 https://doi.org/10.1007/s00347-021-01424-2

Online publiziert: 20. Mai 2021

(c) Der/die Autor(en) 2021

Q

Check for
updates

Alexander C. Rokohl' · Gerhard Welsandt ${ }^{2}$. Ludwig M. Heindl' . Friederike Schaub ${ }^{1}$ · Sigrid Roters ${ }^{1}$

'Zentrum für Augenheilkunde, Medizinische Fakultät und Uniklinik Köln, Universität zu Köln, Köln, Deutschland

${ }^{2}$ Medizentrum Porz, Köln, Deutschland

\section{Erratum zu: Plötzliche bilaterale Visusminderung und Gesichtsfeldausfälle}

\section{Erratum zu:}

Ophthalmologe 2021

https://doi.org/10.1007/s00347-02101392-7

In dem ursprünglichen Artikel wurden die beiden Teilabbildungen 1 a und b vertauscht. Die Online-Version sowie das PDF des Beitrags wurden nachträglich korrigiert. Bitte beachten Sie die korrigierte Abbildung (• Abb. 1).

Der vollständige und korrigierte Artikel steht Ihnen aufwww.springermedizin. de zur Verfügung. Bitte geben Sie dort den Beitragstitel in die Suche ein.

Die Redaktion
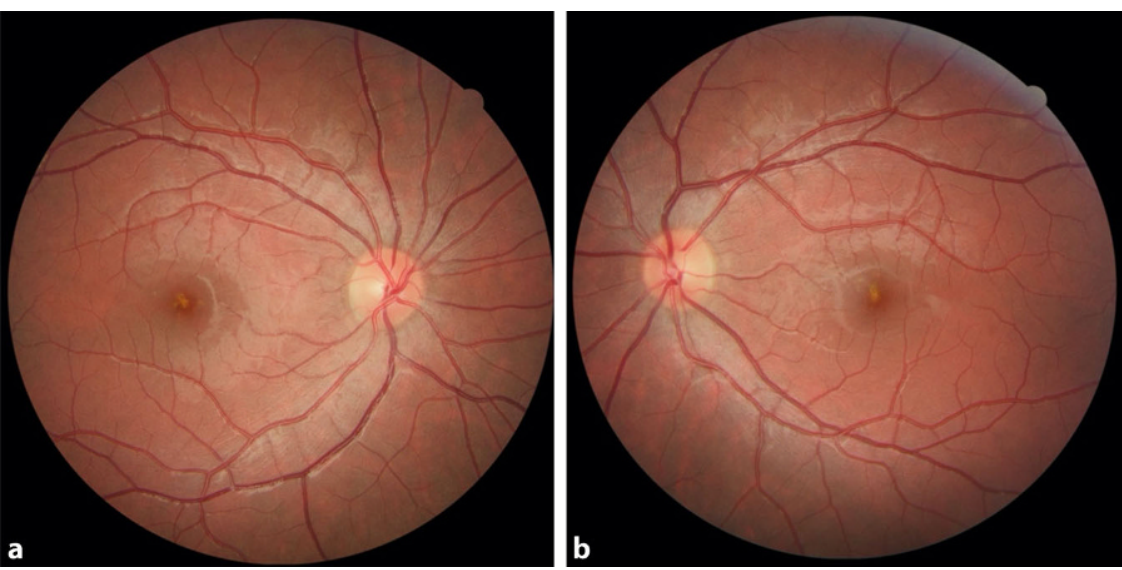

Abb. 1 A Fundoskopisch zeigte sich im Bereich der Makula am rechten (a) und am linken Auge (b) ein vergrößerter fovealer Reflex mit einer gelblichen Läsion und einem dunkleren roten Randsaum

\section{Korrespondenzadresse}

Dr. med. Alexander C. Rokoh

Zentrum für Augenheilkunde, Medizinische Fakultät und Uniklinik Köln, Universität zu Köln Kerpener Str. 62, 50924 Köln, Deutschland alexander.rokohl@uk-koeln.de

Open Access. Dieser Artikel wird unter der Creative Commons Namensnennung 4.0 International Lizenz veröffentlicht, welche die Nutzung, Vervielfältigung Bearbeitung, Verbreitung und Wiedergabe in jeglichem Medium und Format erlaubt, sofern Sie den/die ursprünglichen Autor(en) und die Quelle ordnungsgemäß nennen, einen Link zur Creative Commons Lizenz beifügen und angeben, ob Änderungen vorgenommen wurden.

Die in diesem Artikel enthaltenen Bilder und sonstiges Drittmaterial unterliegen ebenfalls der genannten
Die Online-Version des Originalartikels ist unter https://doi.org/10.1007/s00347-021-01392-7 zu finden.

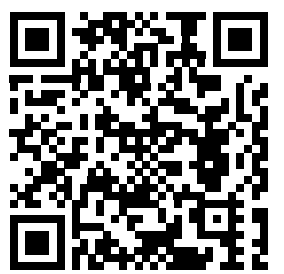




\section{Erratum}

Creative Commons Lizenz, sofern sich aus der Abbildungslegende nichts anderes ergibt. Sofern das betreffende Material nicht unter der genannten Creative Commons Lizenz steht und die betreffende Handlung nicht nach gesetzlichen Vorschriften erlaubt ist, ist für die oben aufgeführten Weiterverwendungen des Materials die Einwilligung des jeweiligen Rechteinhabers einzuholen.

Weitere Details zur Lizenz entnehmen Sie bitte der Lizenzinformation auf http://creativecommons.org/ licenses/by/4.0/deed.de. 